\title{
Subcellular localization of transcripts in Drosophila photoreceptor neurons: chaoptic mutants have an aberrant distribution
}

\author{
John A. Pollock, ${ }^{1,3}$ Mark H. Ellisman, ${ }^{2}$ and Seymour Benzer ${ }^{1,4}$ \\ ${ }^{1}$ Division of Biology 156-29, California Institute of Technology, Pasadena, California 91125 USA; ${ }^{2}$ Department of \\ Neurosciences, Laboratory for Neurocytology, University of California, San Diego, La Jolla, California 92093 USA
}

\begin{abstract}
Photoreceptor neurons in the Drosophila retina are long $(100 \mu)$ and narrow, providing a system for the study of the intracellular distribution of transcripts and proteins. The chaoptic gene is expressed exclusively in photoreceptor neurons, and mutations of the gene result in reduced developmental competence of cells to generate normal rhabdomeric membranes. The mutant protein exhibited altered distribution both in developing and adult photoreceptor neurons. Furthermore, the transcript distribution in mutants was altered, decreasing with distance from the nucleus, instead of the normal uniform distribution throughout the cell soma. The deficit of transcript concentration correlated with the severity of developmental defect in rhabdomere formation along the cell. In contrast, the distribution of the opsin transcript was not affected by the chaoptic mutation. To observe RNA localization at the ultrastructural level, a high-resolution, electron microscopic in situ hybridization protocol was developed. The results indicate that the normal chaoptic transcript is present on the rough endoplasmic reticulum, which may be a vehicle for specific transcript distribution.
\end{abstract}

[Key Words: Retina; photoreceptors; EM in situ hybridization; MAb24B10]

Received November 3, 1989; revised version accepted March 2, 1990.

The development of a neuron involves many informed decisions at the molecular level. A progenitor cell must choose a neural fate above others. Once committed, a cell typically follows a complex sequence of gene expression, morphogenetic movements, and process outgrowth mediated intracellularly by mRNAs and proteins. The Drosophila compound eye offers an excellent system for analyzing the molecular expression of developmentally important genes in the differentiating cell. It contains photoreceptor neurons that are particularly long, with cell bodies extending 100-120 $\mu$ (Fig. 1). Running along the length of the cell body is a rhabdomere (rod-like structure), consisting of a closely packed stack of microvilli formed by infoldings of the cell membrane. The cell projects a precisely targeted axon, $\sim 100 \mu$ long, into the optic ganglia. The cell nuclei of most of the neurons are located near the distal surface of the retina (Fig. 1), so intracellular components must be shuttled over long distances.

Some aspects of the molecular choreography of differentiation in the developing compound eye have been revealed through the use of monoclonal antibodies /Ven-

Current address: ${ }^{3}$ Department of Biological Sciences, Carnegie Mellon University, Pittsburgh, Pennsylvania 15213 USA.

${ }^{4}$ Corresponding author. katesh et al. 1985; Banerjee et al. 1987a,b; Tomlinson and Ready 1987; Tomlinson et al. 1987). In our laboratory, one monoclonal antibody in particular, MAb24B10 (Fujita et al. 1982), was chosen for detailed analysis on the basis of its high degree of specificity for photoreceptors and their axons. It appears during the differentiation of photoreceptor cells in the larval eye imaginal disc. Zipursky and co-workers (1984, 1985; Reinke et al. 1988; Van Vactor et al. 1988) cloned the structural gene for the antigen and characterized it as a membrane-associated glycoprotein. On the basis of conceptual translation of the full-length cDNA, the protein contains 41 amphipathic repeat sequences in a polypeptide of 127 $\mathrm{kD}$, glycosylated to $\sim 160 \mathrm{kD}$. The repeat sequence is similar to ones seen in other proteins known to have membrane-binding properties (Reinke et al. 1988). Van Vactor et al. (1988) generated mutants that express reduced levels of the $24 \mathrm{~B} 10$ antigen and found that they display chaotic organization of the microvilli of rhabdomeres. The gene was accordingly named chaoptic and the two X-ray-induced mutant alleles were designated chp1 and chp2. Analysis of in vitro-synthesized protein (Reinke et al. 1988) and the mutant phenotype (Van Vactor et al. 1988) suggest that chaoptin is an adhesion protein that is required for normal morphogenesis of the rhabdomeric membranes.

Transport and localization of membrane-associated 
Figure 1. Compound eye photoreceptor cells R1-R6 are long. This scale rendering of an ommatidial cluster highlights a single photoreceptor neuron and its axon projecting into the first optic ganglion, synapsing with a lamina interneuron. Drawing on our own observations and the work of TrujilloCenoz and Melamed (1966), Strausfeld (1976), and Ready (1989), we show the outer photoreceptor neurons (R1-R6) extend through the whole depth of the retina. These outer six cells have highly organized rhabdomeric membrane bundles that run the full length along the inner face of each cell. The nuclei of cells R1-R6 are positioned only $20 \mu$ from the corneal lens, placing them some distance from the base of the cell body. Axons for these neurons cross the basement membrane, extending into the first optic ganglia to terminate on specifically targeted secondary interneurons (Braitenberg 1967). Photoreceptor cells R7 and R8 are stacked one on top of the other; their rhabdomeres each extend only partway through the retina (see also Fig. 2A,B). Not shown are the axons for the photoreceptor neurons R7 and R8, which extend greater distances to terminate in the second optic ganglion, the medulla. Also not shown are the hair nerve group, the basement membrane projections of the cone cells, and the tertiary pigment cells. The primary, secondary, and tertiary pigment cells serve to optically isolate each ommatidial cluster.

proteins has long been studied in connection with the rough endoplasmic reticulum, the Golgi apparatus, and the neuronal cytoskeleton (Ellisman and Porter 1980; Hammerschlage et al. 1982; Lindsay and Ellisman $1985 a, b, c)$. The overall implication is that proteins and protein-containing vesicles contain signals for finding their appropriate targets within the cell. The corresponding mRNA transcripts, once exported from the nucleus, must connect up with ribosomes and other cellular machinery for translation into protein. Localization of RNA could contribute to the localization of the protein. The distribution of a particular transcript may be mediated by random diffusion or specific translocation, or its local concentration could be affected by degradation. These mechanisms may be different for each species of mRNA. Individually or in combination, they could lead to subcellular concentration of certain messages, whereas others messages may be uniformly distributed throughout the cell.

Research in recent years has suggested that particular mRNAs have specific subcellular localization. Our own observations on the transcripts of the sevenless gene showed very marked localization in the apical region of the epithelium of developing photoreceptor neurons (Banerjee et al. 1987a). In some cases, RNA may be associated with cellular structures, such as the cytoskeletal framework, which may facilitate transport. Penman and his co-workers have shown by detergent extraction methods that RNA is bound to the cytoskeletal matrix (Lenk et al. 1977; Farmer et al. 1978; Lenk and Penman 1979; Fulton et al. 1980). Particular mRNAs have been shown to have cytoskeletal associations, such as actin mRNA (Bonneau et al. 1985) and frog Vgl mRNA (Pondel and King 1988). In the frog oocyte, animal and vegetal poles, corresponding to the embryo and yolk, accumulate the maternal transcripts An2 and Vg1 asso-

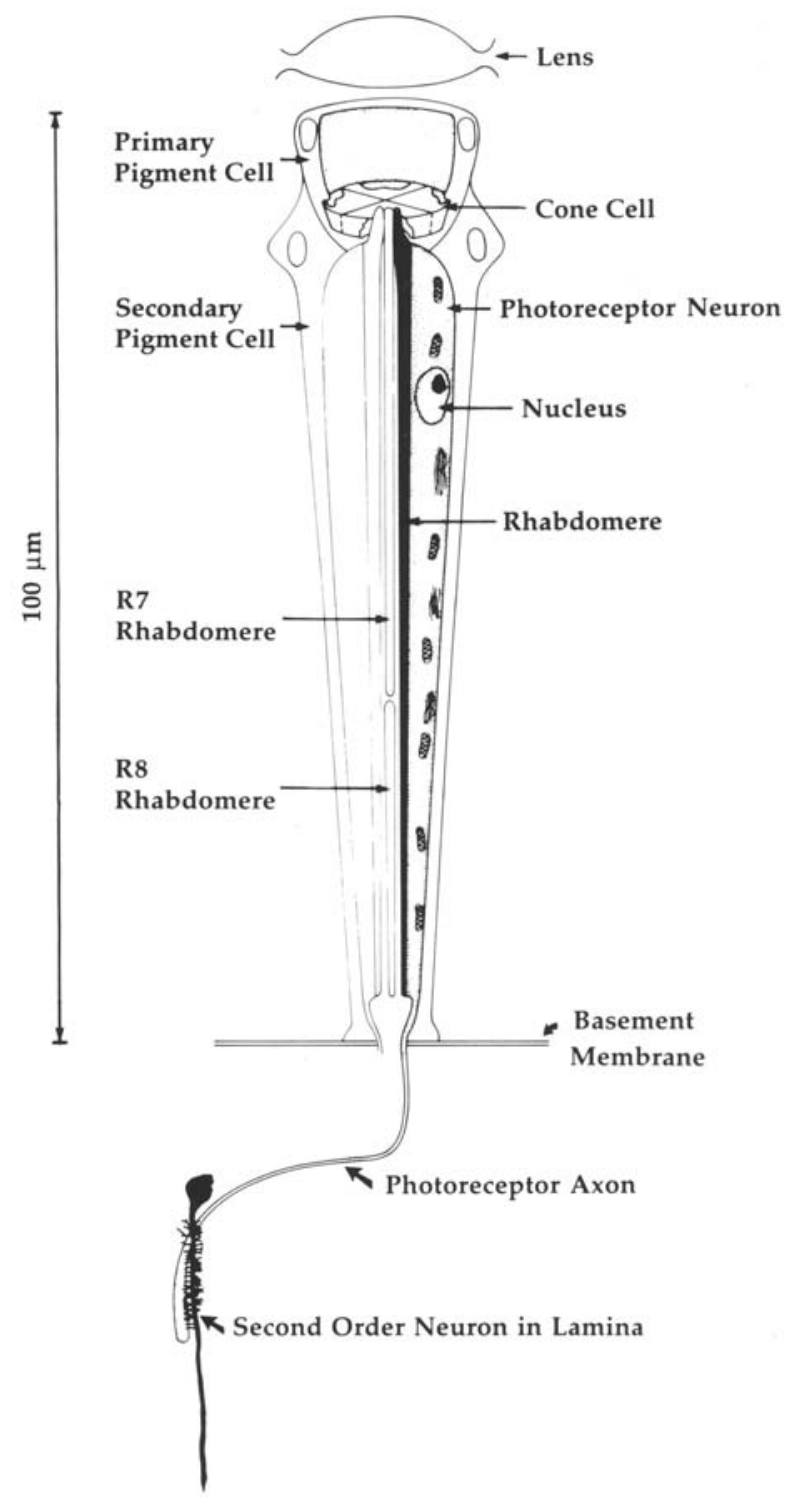

ciated with one pole or the other (Melton 1987; Weeks and Melton 1987a,b). In Drosophila, the maternal transcript bicoid is localized at the anterior of the egg (Nüsslein-Volhard et al. 1987). Certain zygotic messages also can be subcellularly polarized (Edgar et al. 1987; Mlodzik and Gehring 1987; Garner et al. 1988). In cultured chick embryonic muscle and fibroblast cells, specific patterns of transcript localization occur for the cytoskeletal proteins vimentin, actin, and tubulin (Lawrence and Singer 1986; Singer et al. 1989). The majority of these studies have concentrated on giant cells such as oocytes, or cells in culture. Although cells may routinely control the specific localization of particular mRNAs, such cellular control is readily evident only in cells that are large compared to the resolution of the localization technique.

We employed genetics combined with conventional and high-resolution in situ hybridization to study the 
distribution of mRNA in developing and mature photoreceptor neurons. The chaoptic gene transcript is normally present throughout the cell body of photoreceptor neurons. In chaoptic mutants, this distribution is disturbed, whereas the opsin gene transcript distribution is not affected. A defect in membrane organization apparent in chaoptic mutants is spatially correlated with the altered transcript distribution. To investigate mechanisms that may mediate mRNA distribution within cells, we have developed a technique for the subcellular localization of transcripts in ultrastructurally preserved tissue, imaged by high-voltage electron microscopy (HVEM). Observations on chaoptic and opsin mRNA are presented. One model suggested by our results is that transcript distribution may be mediated, in part, by the endomembrane system.

\section{Results}

Photoreceptor cell morphology: normal versus chaoptic mutant

Van Vactor and others (1988) found that the rhabdomeric microvilli are disorganized in the chaoptic mutants. Figure 2 illustrates this for normal and chp1 mutant retinas from 0- to 1-day-old adult flies. Tissue was serially sectioned for EM at different depths from the corneal lens surface. In the section shown at the $20-\mu$ depth, the central rhabdomere corresponds to cell R7 (Fig. 2A,C); at the deeper, 50- $\mu$ plane, the central rhabdomere is from cell R8 (Fig. 2B,D). The nuclei of cells R1-R6 and R7 remain distal during morphogenesis; some can be seen in the $20-\mu$ level sections. The R8 cells move to a proximal position during development; their nuclei are near the base of the retina, at a depth of $\sim 100$ $\mu$, and are thus not seen at the levels of section shown in Figure 2. The rhabdomeres of the R8 cells were not affected as severely in the mutants as were those of $\mathrm{R} 1-\mathrm{R} 6$ and R7. This may be because the soma of cell R8 is much shorter than those of R1-R6, and even somewhat smaller than $\mathrm{R} 7$, so that the gene products in cell R8 have less distance to travel.

\section{Molecular expression during development in normal and chaoptic mutants}

chaoptic transcripts in the eye disc In situ hybridization, using a ${ }^{3} \mathrm{H}$-labeled cDNA probe, was employed to visualize the expression of chaoptic transcripts in the developing eye imaginal disc. In the disc, clusters of photoreceptor cells form in the wake of the advancing morphogenetic furrow, at a rate of $\sim 2 \mathrm{hr}$ per column. Normally, chaoptic expression lags $20-24 \mathrm{hr}$ behind the passage of the advancing morphogenetic furrow. We found that in both chp1 and chp2 mutant discs, transcripts were expressed in the eye disc at the same time in development as in normal discs (Fig. 3). In the two $\mathrm{X}$-ray-induced chaoptic mutants, chp1 and chp2, the transcripts are abnormal (Van Vactor et al. 1988). In chp1, the $4.6-\mathrm{kb}$ transcript and $160-\mathrm{kD}$ protein product appear to be of normal size; however, although the transcript appears to be produced at normal levels, the concentration of the protein (as observed by MAb24B10) is reduced $\sim 10$-fold. On the basis of S1 nuclease analysis, the gene is presumed to contain a point mutation (Van Vactor et al. 1988). In chp2, the $3^{\prime}$ half of the gene is deleted but replaced by a segment of DNA apparently containing a polyadenylation signal, such that a $2.6-\mathrm{kb}$ transcript with a poly(A) ${ }^{+}$tail is produced (Van Vactor et al. 1988). In both chp1 and chp2, the messages appear incapable of endowing the photoreceptor cells with the chaoptin protein needed for normal morphogenesis (Reinke et al. 1988; Van Vactor et al. 1988).

Chaoptin expression during early pupal development In the normal third-instar eye disc, as well as during the first 2 days of pupal development, the 24B10 antigen occurs in both the photoreceptor cell somata and in their axons equally (Figs. 3C and 4A). The particularly abundant expression in the developing optic lobes of the pupa coincides with a period of photoreceptor growth cone elaboration and organization of the neural network in the lamina and the medulla. At $\sim 65-75 \mathrm{hr}$ after puparium formation, the antibody staining in the optic lobes decreases while remaining strong in the retina. This coincides with the elaboration of the photoreceptor cell rhabdomeres (Van Vactor et al. 1988). In the adult, the retina continues to stain strongly; the protein may be in high demand because of the turnover of the photoreceptor membranes (Carlson and Chi 1979). The staining in the adult lamina and medulla are weaker yet adequate to visualize the projections of the photoreceptor axons to their targets.

In the mutant chp1, abnormal distribution of the antigen becomes evident early in development. Although the antigen accumulates in the eye disc photoreceptor cell body, the level in the axons is reduced compared to wild type (Fig. 3F). Later, in the mutant pupa, the antigen continues to be distributed incorrectly. At a time when the protein is normally abundant in the photoreceptor axons projecting into the developing lamina (Fig. $4 \mathrm{~A} \mid$, very little staining appeared in the chp1 mutant, whereas staining was evident in the cell bodies (Fig. 4C). In the more extreme mutant, chp2, little, if any, antigen could be detected in the third-instar eye disc (Fig. 3I), the pupa, and the adult retina (data not shown).

Transcript distribution during photoreceptor terminal differentiation Some 3 days into pupal development, the compound eye begins its terminal differentiation; in each ommatidium, cell R8 drops to the basal one-third of the retina, with its nucleus moving to the base of the cell. Cells R1-R6 and R7 begin to elongate inward, leaving their nuclei near the apical poles of the cells. During this time, the photoreceptor rhabdomeric membranes start to develop, beginning at the apical pole of each cell and progressing down to the base (Van Vactor et al. 1988). The elongation of the cells is evident in Figure 5, A and B, where the thickness of the retinal epithelium increases. The distribution of the normal 

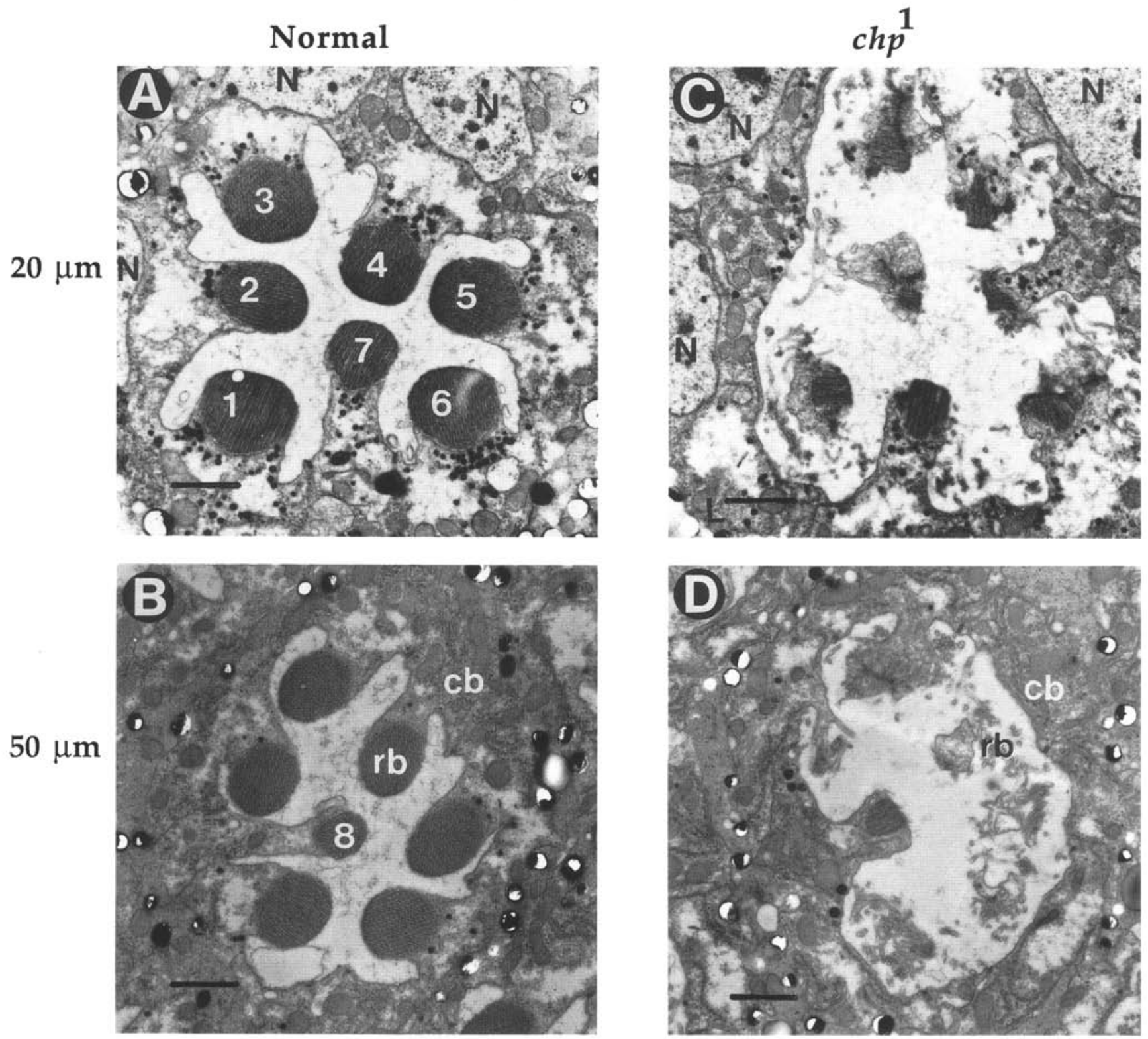

Figure 2. chaoptic mutations affect rhabdomere formation more severely in the proximal retina. Transmission EM of two different levels in the adult retina of normal and chp1 mutant allele is shown. In the mutant, the disorganization and paucity of rhabdomeres become more severe deeper into the retina. Serial section depth is measured from the lens cornea. Bar, $1.0 \mu$. (A) Normal ommatidial cluster at a $20 \mu$ depth. The rhabdomere for cell R7 is evident in the center of the cluster. Photoreceptor cell nuclei (N) are evident at this depth. The nuclei for cells R1-R7 are positioned distally. The nuclei for R8 cells are below a $50 \mu$ depth. $(B)$ Normal ommatidial cluster at $50 \mu$. The rhabdomere for cell R8 is evident in the center of the cluster. (rb) Rhabdomere bundle of microvilli, (cb) cytoplasmic cell body. $(C)$ chaoptic mutant chp1 ommatidial cluster at a $20 \mu$ depth. The rhabdomeric membranes are disorganized. The nuclei $(\mathrm{N})$ and cytoplasm appear to be normal. $(D)$ chaoptic mutant chp1 ommatidial cluster at $50 \mu$. Only the rhabdomere for cell R8 is clearly evident, found in the center of the cluster. The rhabdomeres for cells R1-R6 are extremely disorganized, whereas the cell bodies are intact. (rb) The underdeveloped chaotically organized rhabdomeric microvilli; $(\mathrm{cb})$ the cytoplasmic cell body appears intact and normal.

chaoptic transcript initially lags behind the elongation of the cells seen $75 \mathrm{hr}$ after puparium formation (Fig. 5B). The expression of chaoptic transcript in mutant chp2, $75 \mathrm{hr}$ after puparium formation, is very similar to that of the normal retina. The distribution of the transcript lags behind the elongation of the cells.
The Drosophila opsin gene Rh1, which is specifically transcribed in photoreceptor cells R1-R6 (O'Tousa et al. 1985; Zuker et al. 1985; Pollock and Benzer 1988), was examined in relation to these developmental events. The opsin transcript was first detected in the developing retina at $\sim 70-75 \mathrm{hr}$ after puparium formation (Fig. 5); 

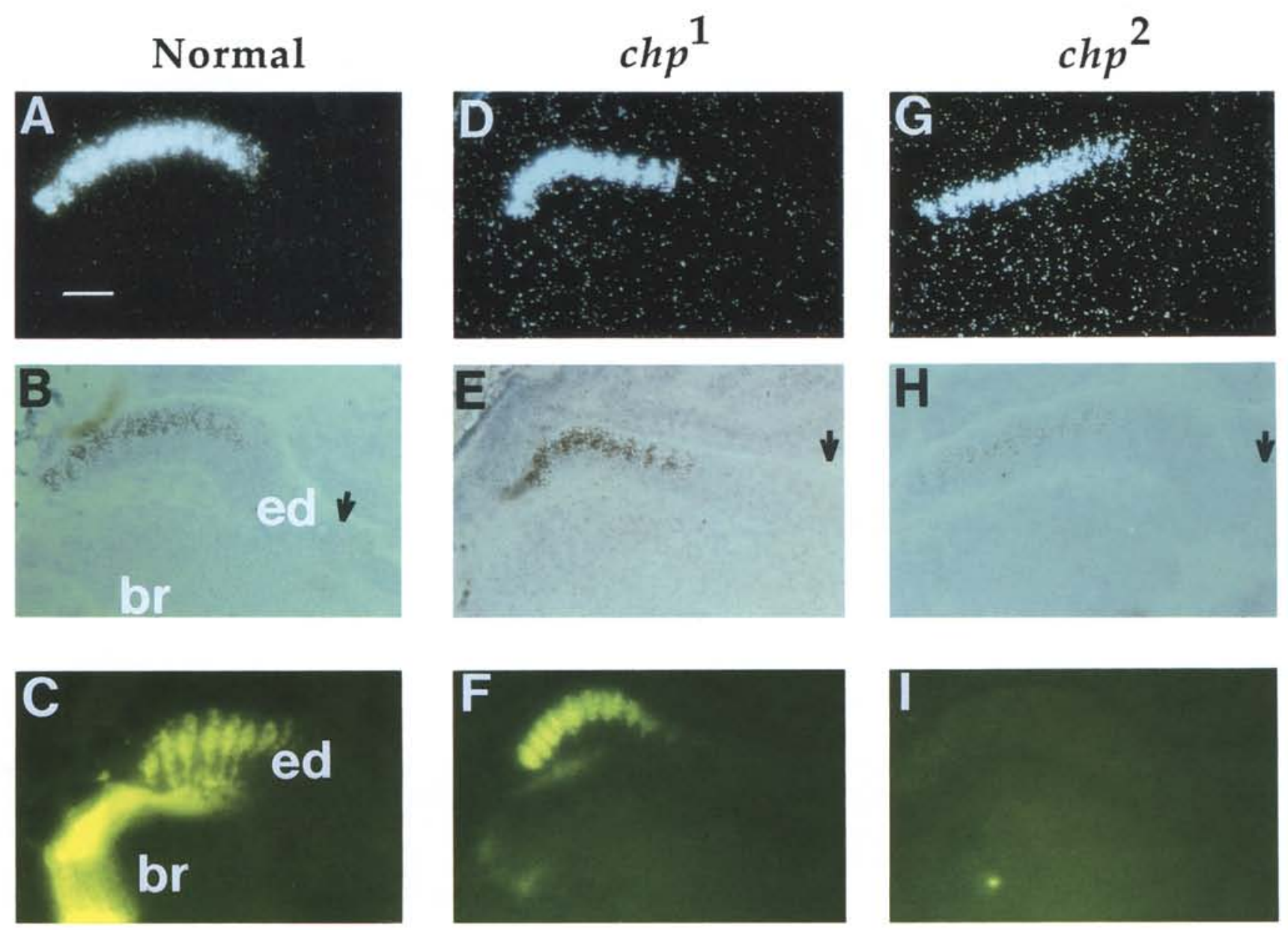

Figure 3. (See facing page for legend.)

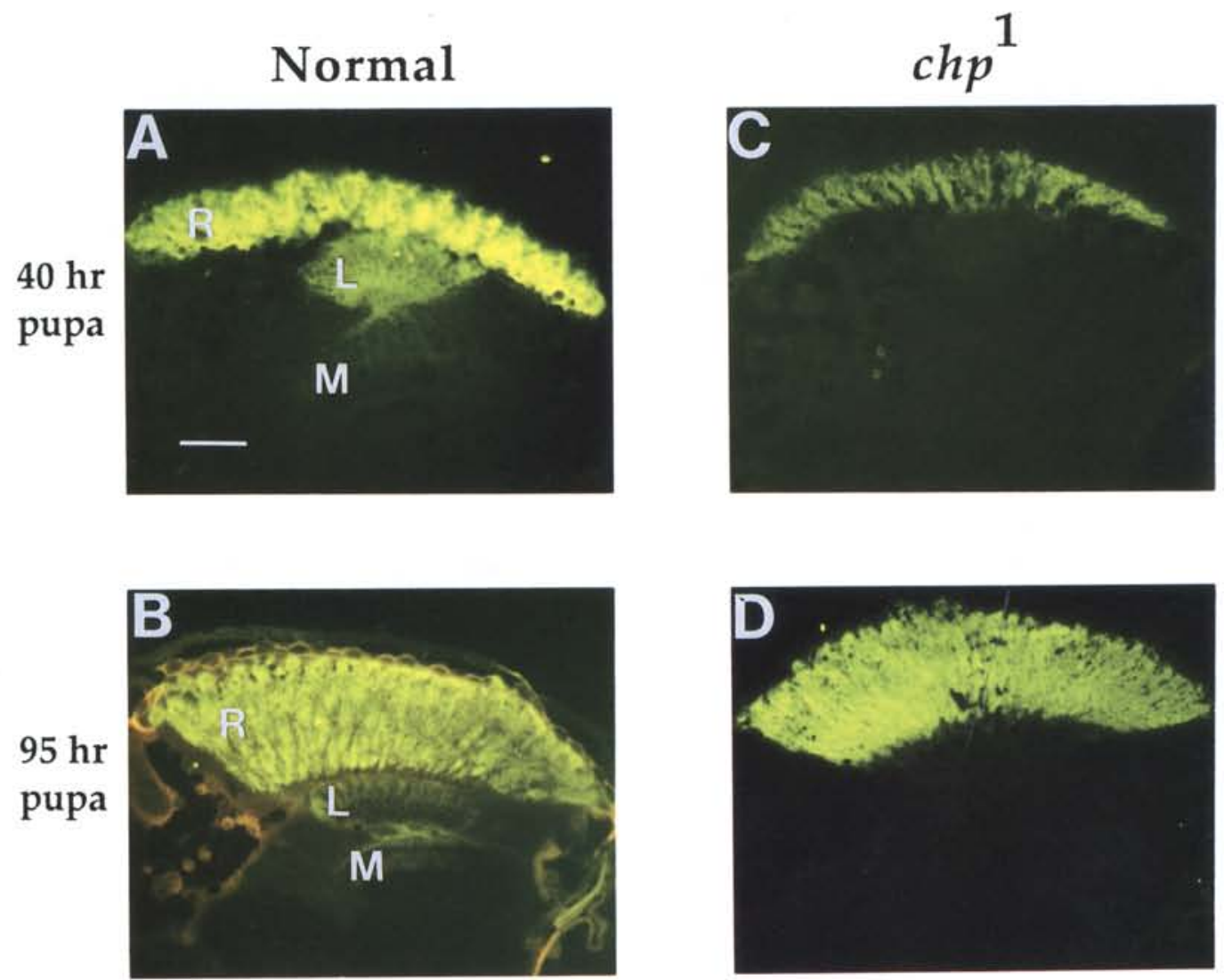

Figure 4. (See facing page for legend.) 
the opsin protein is not made until the membrane that it will reside in is present. Like the normal chaoptic transcript, its distribution appeared to initially lag behind cell elongation. Eventually, however, both chaoptic and opsin transcripts filled the lengths of the cell bodies in normal flies.

Subcellular distribution of chaoptic transcripts in adult photoreceptor cells In normal adults, the chaoptic mRNA was distributed throughout the $100-120-\mu$ depth of the photoreceptor cell somata, a slightly higher signal being apparent near the base of the retina, where photoreceptor cell R8 is located. In contrast, the chaoptic mRNA transcripts for chp1 and chp2 showed abnormal distributions. Both alleles exhibited graded signals, decreasing proximally (Fig. 6C,E). The gradient was steeper for the more severe chp2 allele (Fig. 6C). The distribution of the chaoptic mRNA seen in both mutants correlated with the graded defect in rhabdomere organization, which was also more severe in the proximal retina (Fig. 2).

To test whether the abnormal distribution of chaoptic mutant transcript could be the result of a general defect in mRNA transport in the mutant cell, the opsin Rhl mRNA was probed for comparison. Like chaoptin, opsin $\mathrm{Rh} 1$ is an integral component of the rhabdomere (O'Tousa et al. 1985; Zuker et al. 1985). In normal flies and in chaoptic mutants, an essentially normal distribu- tion of opsin mRNA was found. This was true even in chp2, the more extreme chaoptic allele (Fig. 6E-G). Therefore, the gradient observed for the chaoptic transcripts in the chaoptic mutants cannot be attributed to a lack of integrity of the photoreceptor cells or to a generalized alteration in mRNA distribution. The distributions of the two species of transcript were independent, only the chaoptic one being affected by chaoptic mutations.

As a reciprocal control, the Rhl opsin transcript was deleted by use of the nina $\mathrm{E}$ deficiency mutant Df(3R)oI17 (O'Tousa et al. 1985). The retina of this mutant showed no hybridization with the opsin Rhl DNA probe (Fig. $6 \mathrm{H}$ ). Nevertheless, in this mutant, the normal chaoptic transcript was expressed at an approximately normal level and with a normal distribution (Fig. 6D). The 24B10 antigen was also expressed normally in the deficiency mutant (data not shown). This provided further evidence that the cellular distributions of chaoptic and opsin transcripts are independent.

\section{High-resolution localization of gene products}

Visualization of organelles associated with the mRNA would help to guide our thinking on possible mechanisms controlling transcript distribution. To facilitate this analysis, a higher resolution procedure for in situ hybridization, adapted to the EM, was developed.

Figure 3. Molecular probes reveal the normal and mutant expression of the chaoptic gene products. Cryostat sections of horizontally oriented 0- to 3-hr "white" prepupae were cut to reveal gene expression through the depth of the developing eye imaginal disc and in the photoreceptor axons projecting into the brain. In the chp1 allele, the temporal and tissue specificity of expression of the chaoptic mutant transcripts are normal, but the MAb24B10 antibody staining reveals that the antigenic protein expressed in the photoreceptor cell soma does not appear to be correctly transported into the axons. The chp2 mutant allele does not appear to make any antigenic protein. The anterior of the animal is toward the top of the page; the midline is toward the right. The arrow marks the approximate position of the morphogenetic furrow. Bar, $50 \mu$. (A) Dark-field illumination reveals the refractive silver grains of the hybridization signal over the eye disc for a normal (wild-type, O-R) 0- to 3-hr white prepupa. (B) Corresponding phase illumination photomicrograph of the section shown in $A$. (ed) Eye disc; (br) brain. $(C)$ In a similar plane of section for a 0-to 3-hr staged prepupa, epifluorescent illumination reveals the FITC-labeled MAb24B10 staining of the chaoptin protein in the photoreceptor cell cluster of the developing eye disc, as well as the axons projecting into the developing optic lobes of the brain. (ed) Eye disc; (br) brain. (D) Dark-field illumination shows the silver grains of the hybridization signal over the eye disc for a chp1 mutant allele 0- to 3-hr white prepupa. $(E)$ Corresponding phase photomicrograph of the section in $D .|F|$ In a similar plane of section for a 0- to 3-hr staged chp1 mutant prepupa, epifluorescent illumination reveals the FITC-labeled MAb24B10 staining of the chaoptin protein in the photoreceptor cell cluster of the developing eye disc. Though there is staining in the cell bodies, there is not significant staining in the photoreceptor cell axons. $(G)$ Dark-field illumination shows the silver grains of the hybridization signal over the eye disc for a chp2 mutant allele 0- to 3-hr white prepupa. Though the intensity of the silver grain signal appears reduced as compared to normal and chp1, this may reflect the fact that the 3 ' half of the the gene is deleted in this mutant. A full-length cDNA probe was used, so that the apparent signal would be approximately half of that seen in wild type. $(H)$ Corresponding phase photomicrograph of section in $G$. $(I)$ In a cryostat section of a similarly staged chp2 mutant prepupa, epifluorescent illumination does not reveal any significant MAb24B10 staining.

Figure 4. Abnormal distribution of chaoptin in mutant chp1. Analysis of chaoptin protein expression during pupal development for normal and chp1 mutant flies reveals an abnormal distribution of the protein in the mutant (in fluorescence micrographs). Normally, the chaoptin protein is abundant in the developing optic lobes, especially the lamina through the first two-thirds of pupal development. In the mutant, very little, if any, protein is apparent in the photoreceptor cell axons. (R) Retina; (L) lamina; (M) medulla. Bar, 50 $\mu$. $(A)$ Cryostat section of a normal 40-hr pupa stained with MAb24B10. Staining is intense in the retina and the photoreceptor axons projecting into the first and second optic ganglia of the brain. (B) Cryostat section of a normal 95-hr pupa stained with MAb24B10. The nearly mature eye has an abundance of chaoptin in the retina with moderate expression of the protein apparent in the photoreceptor axons in the brain. $(C)$ Cryostat section of a chp1 mutant 40-hr pupa stained with MAb24B10. Staining is apparent in the retina and is not detected in the brain. (D) Cryostat section of a chp1 mutant 95-hr pupa stained with MAb24B10. Staining is apparent in the retina and is not detected in the brain. 
Pollock et al.

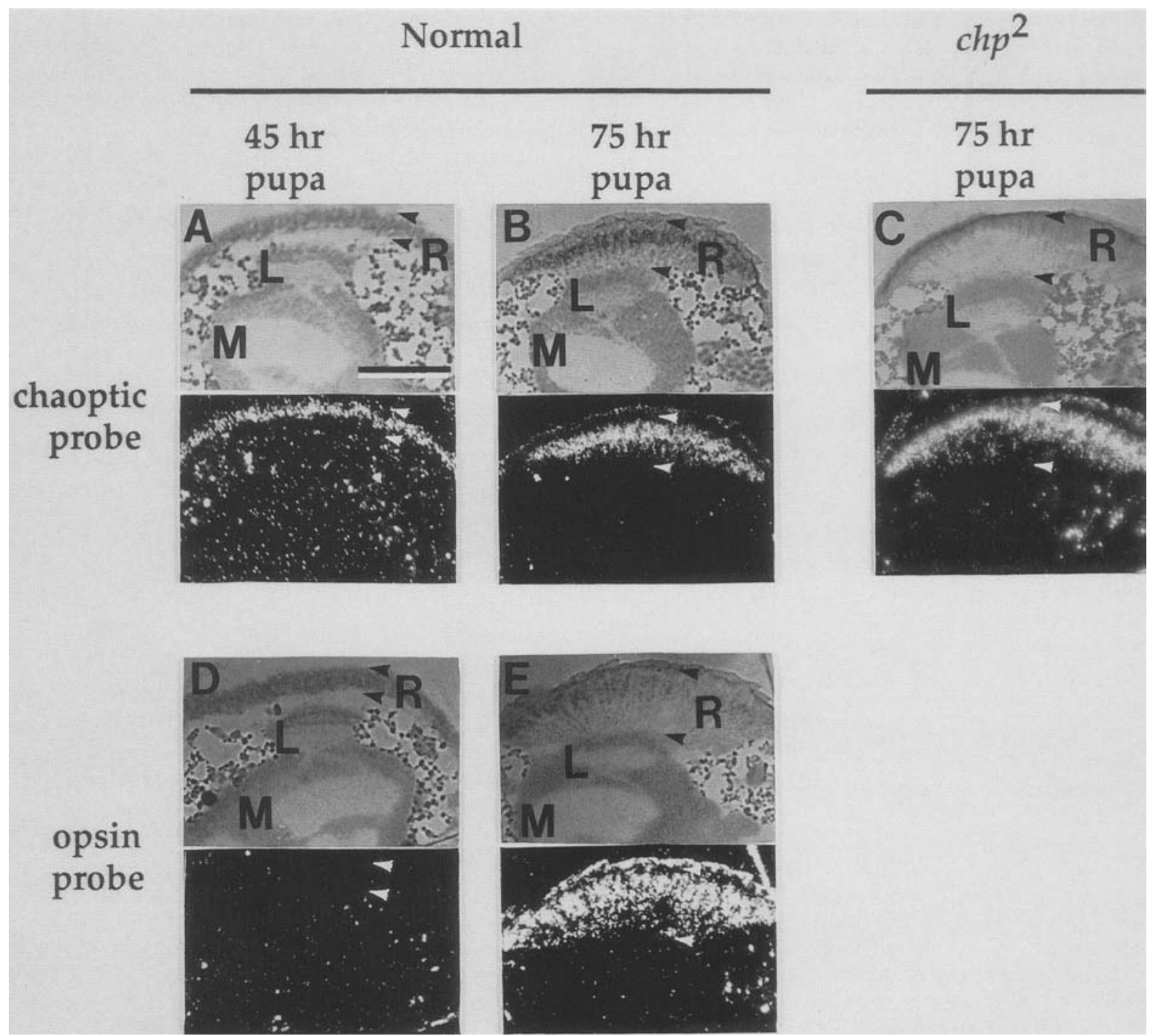

Figure 5. Distribution of chaoptic and opsin transcripts during pupal development in normal and in chp1 mutant retina. Terminal differentiation of the photoreceptor neurons is evident at $70-75 \mathrm{hr}$ after puparium formation. In these cryostat sections of horizontally oriented pupal heads, the tissue of the developing retina is apparent. The changing depth of the retina is evident in comparison of the 45- to 75-hr views. Both phase photomicrograph and dark-field images of the same area are shown, the dark-field illumination revealing the distribution of transcript. (R) Retina; (L) lamina; $(M)$ medulla. Arrowheads mark the apical and basal boundaries of the retina. (A) chaoptic mRNA expression in normal retina $\sim 45 \mathrm{hr}$ after puparium formation. The transcript is distributed throughout the depth of the retina, which is rather shallow at this stage. Bar, $100 \mu .(B)$ chaoptic mRNA expression in normal retina $\sim 75 \mathrm{hr}$ after puparium formation. The photoreceptor cells are elongating, extending deeper into the head. The distribution of the transcript shows a gradient, decreasing with depth. $|C|$ chaoptic mRNA expression in the chp 2 mutant retina at $75 \mathrm{hr}$ after puparium formation. The gradient is similar to that seen in the normal retina at this stage. Until this stage in pupal development, the photoreceptor cells in both chp1 (not shown) and chp2 appear as in the normal fly. From this point on, however, overt development is impeded in the mutants. $(D)$ In normal retina $\sim 45 \mathrm{hr}$ after puparium formation, opsin mRNA is not yet expressed. (E) Opsin mRNA expression in normal retina $\sim 75 \mathrm{hr}$ after puparium formation. As terminal differentiation progresses, the opsin transcript becomes expressed. The distribution of the transcript appears as a gradient that decreases with depth in the elongating photoreceptor cells.

EM study of opsin expression The high-resolution EM in situ hybridization involved mild aldehyde fixation of dissected tissue, sucrose cryoprotection, and cryosectioning on an ultramicrotome. Probe DNA, labeled by nick-translation with biotinylated nucleotides, was sizeselected for lengths of $\sim 50-250 \mathrm{bp}$, and hybridization was performed on the sectioned tissue. The tissue was then post-treated as for immunolabeling (Tokuyasu 1984; Van den Pol et al. 1989). HVEM at $1 \mathrm{MeV}$ enabled us to use thick sections $(0.5-1.5 \mu \mathrm{m})$, providing for greater maintenance of integrity of the tissue through the steps of immuno- and colloidal-gold labeling. 

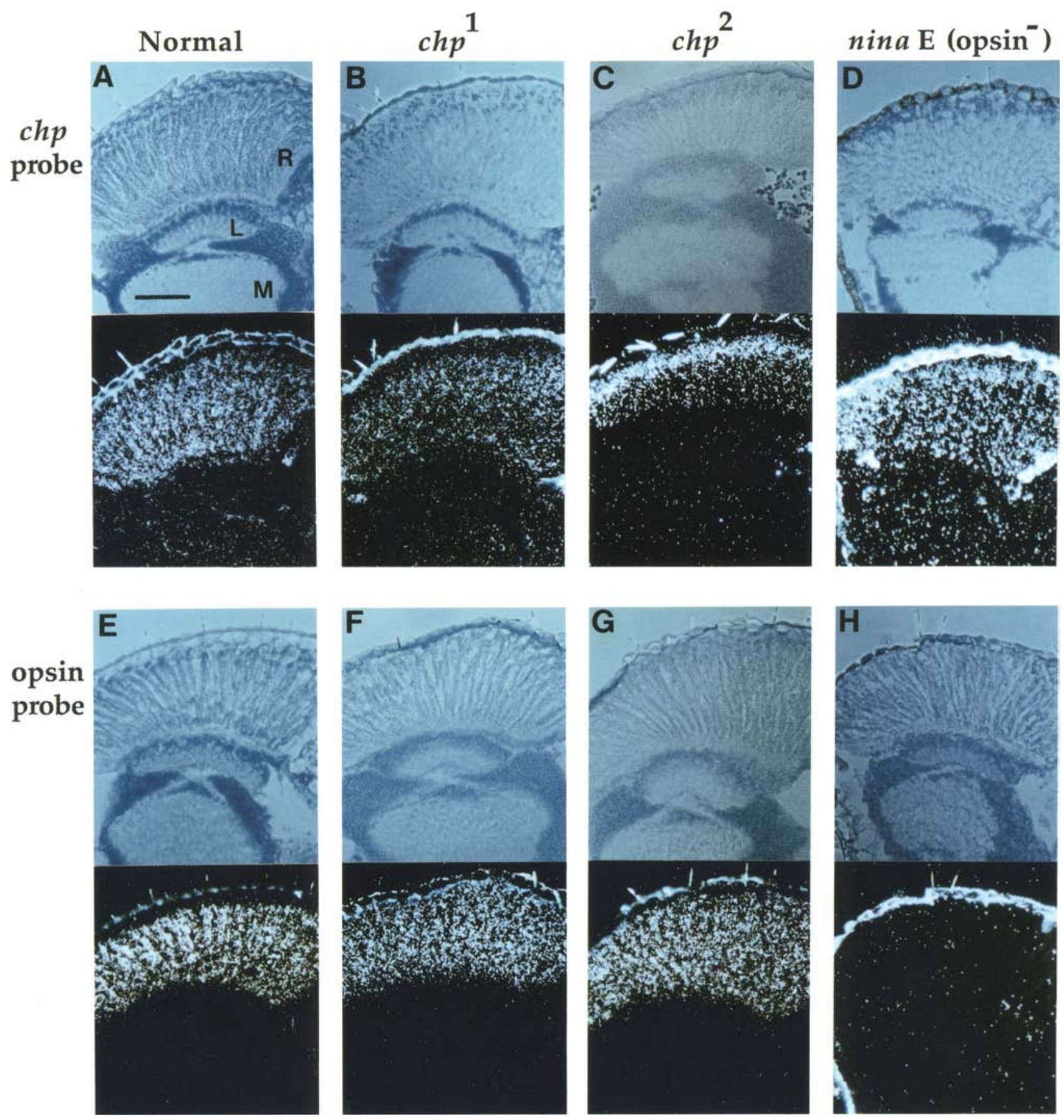

Figure 6. Comparison of the chaoptic and opsin transcript expression in normal and mutant adult heads. Comparing normal expression to two chaoptic mutant alleles and the ninaE mutant, deficiency $D f(3 R)$ oI17, which lacks opsin Rh1. Both phase photomicrograph and dark-field images of the same field of view are shown from newly emerged adult flies. The dark-field photomicrographs highlight the silver grains of the hybridization signal in these cryostat sections of adult heads. (R) Retina; (L) lamina; (M) medulla. (A) chaoptic mRNA expression in normal adult retina. The transcript is distributed throughout the depth of the retina. Bar, $50 \mu$. (B) chaoptic mRNA expression in the chp1 mutant adult retina. The distribution of the transcript is in a gradient that decreases with depth. $(C)$ chaoptic mRNA expression in the chp2 mutant adult retina. The gradient is severe with little mRNA expression in the lower retina. $(D)$ chaoptic mRNA expression in the ninaE mutant [Df(3R)oI17] adult retina. The chaoptic transcript is distributed normally, although the rhabdomeres in this mutant are truncated and underdeveloped. $(E)$ Opsin Rh1 mRNA expression in normal adult retina. The transcript is distributed throughout the depth of the retina. $(F)$ Opsin Rhl mRNA expression in the chp1 mutant adult retina. The distribution of the transcript is normal even though the chp1 rhabdomeres are mutant. However, the cell bodies are still reasonably intact (see Fig. 2). (G) Opsin Rh1 mRNA expression in the chp2 mutant adult retina. The distribution of the transcript is normal even though the chp2 rhabdomeres are nearly all missing. However, the cell bodies are still intact. ( $H$ ) Test for opsin Rhl mRNA expression in the ninaE mutant [Df(3R)oI17] adult retina. As expected, no transcript is detected. 
Figure 7A shows a sketch of a HVEM montage of a single ommatidial cluster from a normal retina. This $\sim 1-\mu$-thick cryosection was probed with a biotin-labeled, Rhl opsin cDNA. The black ink spots indicate the positions of all the colloidal-gold particles relative to the rhabdomeric membranes. The in situ hybridization signal was clearly evident in the cytoplasmic regions, where the opsin protein is presumably synthesized, but not in the rhabdomeres or the extracellular matrix between the photoreceptor cells. Figure 7B shows lat higher magnification) the single cell indicated by the box in Figure 7A. Here, the actual colloidal-gold particles can be observed. They occur in the cell cytoplasm; only background is apparent in the rhabdomeric microvilli.

For comparison, Figure $7 \mathrm{C}$ shows a sketch of a conventional electron micrograph $(100 \mathrm{KeV})$ of localization of the opsin protein in a $0.2-\mu$ cryosection, by using a monoclonal antibody specific to opsin Rhl. This antibody was generated by Gert de Couet and Tanimura (1987). Figure 7D shows (at higher magnification) the cell in the box in Figure 7C. In contrast to the transcript, the opsin protein is abundant in the rhabdomeric membranes of cells R1-R6 but is sparse in the cytoplasm (Fig. 7C,D).

Analysis of the opsin transcript here serves two functions. First, both the opsin protein and the chaoptic protein normally localize in the rhabdomeric membranes, possibly employing similar mechanisms, so opsin serves as an appropriate control. Second, the abundance of the transcript helps to confirm the reliability of this highresolution procedure. Several features must be considered when comparing these electron micrographs. The tissue sections probed for RNA in the HVEM studies were 5-10 times thicker than those probed for protein, and the pretreatments were quite different for the two procedures. In addition, images obtained by conventional EM ( $100 \mathrm{KeV})$ are of quite different contrast from those produced by HVEM (1000 KeV). To properly interpret the signal obtained using the newly developed HVEM in situ technique, we compared the EM observations to light microscopic data and also carried out independent control experiments for both the EM RNA localization and the EM protein localization. Because an RNA generally has a much smaller copy number per cell than the corresponding protein, the RNA controls were more critical. To establish the background level for the RNA localization, our negative controls included (1) exhaustive pretreatment of the cryosectioned tissue with RNase A, (2) application of DNA probes that lacked biotin, (3) use of biotin-labeled probes for molecules that are not expressed in the tissue under study, and (4) use of genetic mutants that do not make the RNA of interest. All of these preparations exhibited low-level, random distributions of colloidal gold (data not shown). By quantitating the gold particle density per unit area of comparable tissue in experimental and negative control tissue sections, we found an average signal-to-noise ratio of $\sim 4: 1$. This value was close to the whole-cell signal-tonoise ratio of $6: 1$ reported by Singer and others (1989) for their EM in situ hybridization technique, using detergent-extracted, whole-mount cultured cells.

Two points must be considered when determining the organelle with which the colloidal-gold signal was associated. First, the tissue section was rather thick; an organelle that appeared to be associated with the gold signal could actually be at an underlying plane. Stereomicroscopy would thus be helpful. A second consideration is the signal-to-noise ratio. To evaluate this, we compared large areas of cytoplasm, imaged in several independent experiments, to assay trends in association of gold signal with organelles. Two organelles exhibited a high degree of association with the signal: the cell nucleus, where pre-RNAs reside, and the endoplasmic reticulum, where the mature transcripts may be associated with ribosomes on the rough endoplasmic reticulum.

In the case of opsin Rhl protein localization, the useful internal control that cell R7 does not express Rh1 was available. The $R 7$ cell indeed gave a very low colloidal-gold signal (Fig. 7C). The signal-to-noise level of immunogold detection of the opsin protein, calculated by comparing the average particle density per unit area of rhabdomeres $\mathrm{R} 1-\mathrm{R} 6$ to the particle density of rhabdomere R7, was $11: 1$.

chaoptic RNA is regionally localized on the rough endoplasmic reticulum Figure 8 shows a HVEM montage of in situ hybridization of a retina section probed for chaoptic mRNA; Figure $8 \mathrm{~B}$ depicts a sketch of the nucleus shown in Figure 8A, illustrating the configuration of the rough endoplasmic reticulum relative to the nuclear envelope. In this $1-\mu$ cryosection through the distal nucleus of a photoreceptor cell, the gold signal for chaoptic RNA, seen just outside the nucleus, was not evenly distributed. Rather, it appeared in a restricted patch of the rough endoplasmic reticulum. This photograph is typical of results obtained with several independent experiments. This suggests that the gene product may be marked for specific targeting, even as it exits the nucleus. Figure $8 \mathrm{C}$ shows (at higher magnification) a region of the tissue section, rich in rough endoplasmic reticulum, that had a particular abundance of colloidalgold signal. Similar experiments, using a probe for opsin RNA, gave signals that also appeared to be associated with regions of the cytoplasm rich in rough endoplasmic reticulum (data not shown). In preliminary HVEM analysis of transcripts in chaoptic mutants, the relative density of gold particles decreased approximately twofold with distance from the nucleus, consistent with the light microscopic results shown in Figure 6, though the images were somewhat confounded by the cellular disorganization caused by the mutant defects.

\section{Discussion}

\section{Normal expression of products of the chaoptic gene}

The normal chaoptic transcript is $4.6 \mathrm{~kb}$ long with 258 bp of 5'-untranslated sequence and 1004 bp of 3 '-untranslated sequence (Reinke et al. 1988). The transcript 

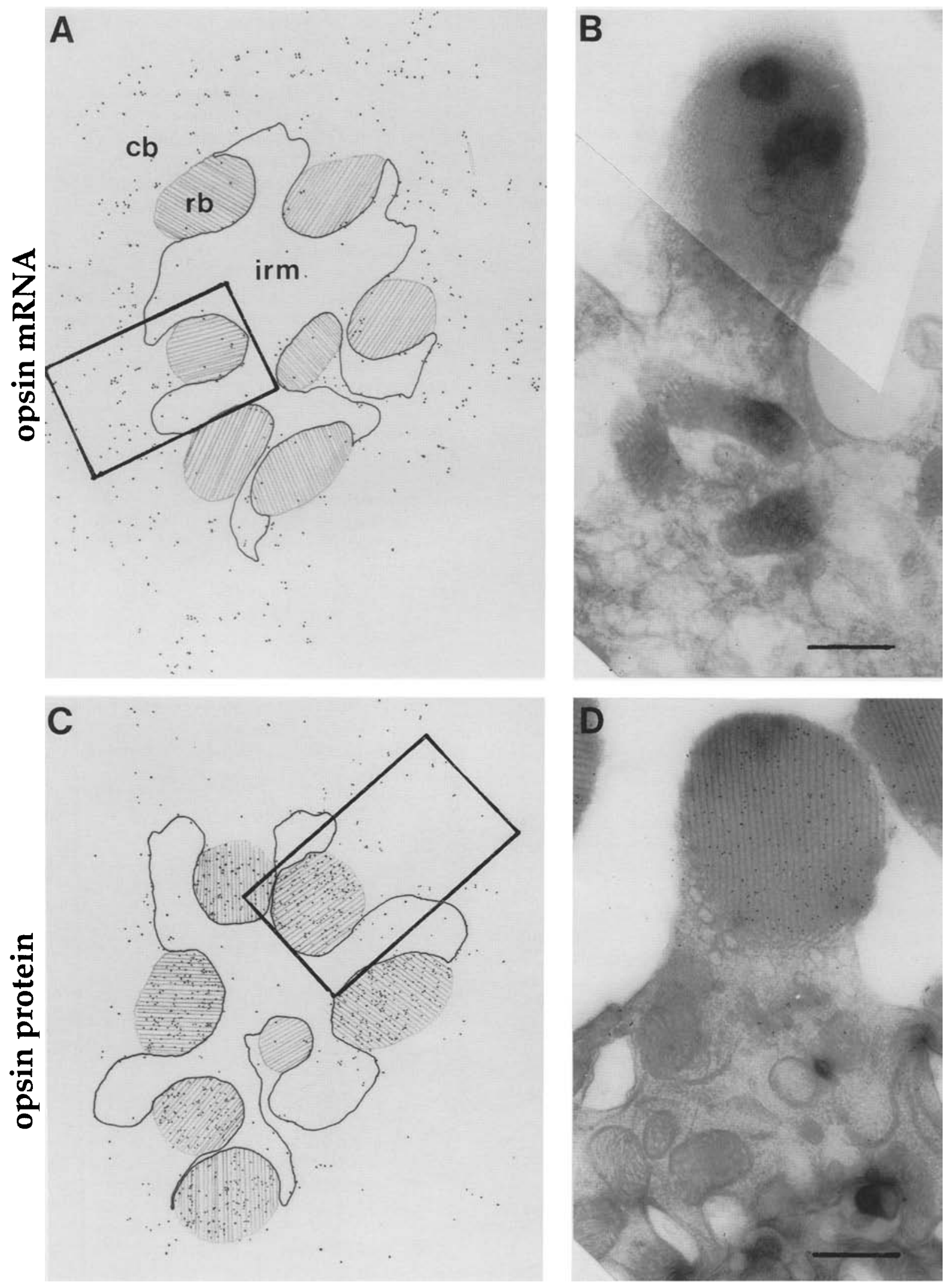

Figure 7. (See following page for legend.) 
encodes a 127-kD polypeptide with a 30-amino-acid, aminoterminal signal peptide (Reinke et al. 1988). The mature protein is glycosylated to a molecular mass of $\sim 160 \mathrm{kD}$. The fly has three types of visual organs: the adult compound eye, the larval photoreceptor organ, and the adult ocellus. The photoreceptor cells of all these organs have rhabdomeric processes, ranging from relatively crude membrane folds in the larval eye to the exquisitely stacked microvilli of the adult compound eye (Pollock and Benzer 1988). Both chaoptic transcript and protein are expressed in all three (Zipursky et al. 1984; J.A. Pollock and S. Benzer, unpubl.). In the eye disc, the expression of chaoptic transcript and protein in a given column of photoreceptor clusters begins $20-24 \mathrm{hr}$ after the initial formation of the clusters behind the advancing morphogenetic furrow. This suggests that chaoptin is not needed for the primary differentiation of these cells as neurons, nor as photoreceptor cells but, rather, to contribute to later stages in their differentiation (Venkatesh et al. 1985). From the onset of expression and throughout the remaining development of the compound eye, chaoptic mRNA was found in cell bodies, but not in axons (illustrated in Fig. 3A,B). The protein, on the other hand, was found in both regions, presumably being transported from the cell body into the axons (Fig. 3C).

\section{Expression in chaoptic mutants}

In chp1, sufficient antigen was detectable to see that the defective protein is abnormally distributed within the developing photoreceptor neurons; little, if any, of the protein finds its way from the cell bodies into the photoreceptor axons. Because chaoptin has been suggested to act as a photoreceptor-specific adhesion molecule (Reinke et al. 1988; Van Vactor et al. 1988), it may conceivably have a role in establishing and maintaining neural connections in the optic lobes. If so, the reduced levels of chaoptin in the optic ganglia of the two mutants might be expected to cause abnormalities, even in development of the lamina and medulla. Nevertheless, in a preliminary analysis of the adult lamina, Van Vactor et al. (1988) found no gross abnormalities in the more severe chp2 allele. The abundant expression concomitant with lamina and medulla development is an interesting observation that may warrant further investigation.

We found that in both chaoptic mutant alleles, the chaoptic mRNA transcripts were distributed abnormally, paralleling the graded deficit in microvillar organization. The mutation's effect appeared to be specific to the chaoptic mRNA; it did not appear to affect other transcripts, such as the opsin Rhl, despite the fact that the opsin and chaoptin proteins are both abundant in photoreceptor membranes and may be processed normally by the cell in a similar fashion.

During pupal development, a transition in cellular organization and gene expression was evident at $\sim 65-75$ $\mathrm{hr}$ after puparium formation. The terminal differentiation of the photoreceptor cells was marked by cellular rearrangement and elongation, the eight photoreceptor cells establishing their adult placement and dimensions. Lagging behind cell elongation was the formation of the photoreceptive membranes, the rhabdomeric microvilli, which began at the outermost ends of the cells near the nucleus. Apparently coupled to this elaboration of photoreceptor membrane was the onset of expression of the opsin gene and the overall expression of the chaoptic gene, the latter presumably to provide its function as an adhesion protein to stabilize the rhabdomeric microvilli. At this stage of development, our observations showed that the normal chaoptic transcript occurred as a gradient throughout the length of the photoreceptor cell soma, although its distribution lagged behind the cell's elongation (Fig. 5). The opsin transcript was similarly distributed throughout the developing photoreceptor cell soma, lagging behind cellular elongation. In normal flies, these gradients disappeared, but in the chaoptic mutants, an abnormal transcript distribution became evident.

Because the opsin protein becomes incorporated into the microvillar membranes, it makes sense that opsin transcription is also coupled to the production of the rhabdomere. Several other genes, believed to be involved in sensory transduction, are also transcribed at this late pupal stage (Montell et al. 1985, 1987; O'Tousa et al. 1985; Zuker et al. 1985, 1987; Cowman et al. 1986; Fryxell and Meyerowitz 1987; Bloomquist et al. 1988; Schaeffer et al. 1989; Shieh et al. 1989; Hyde et al. 1990; Smith et al. 1990), and the same may be true of others in the phototransduction cascade.

\section{Control of transcript distribution}

The abnormal distribution of the mRNA observed in chaoptic mutants could be a result of the mutant transcripts being abnormally susceptible to degradation, so

Figure 7. EM localization of opsin Rhl RNA and protein in the compound eye photoreceptor cells. $(A)$ Sketch of opsin Rh1 RNA localization in a $1-\mu$ cryosectioned retina from a newly emerged fly. This single ommatidium is reconstructed from a montage of HVEM photomicrographs. The data are presented in this manner to reveal the overall distribution of the colloidal-gold particles relative to the rhabdomeres (rb), the intraretinular matrix (irm), and the photoreceptor cell bodies (cb). Each spot represents the position of an individual gold particle. The signal is apparent in the cell bodies but not in the rhabdomeres or in the intraretinular matrix. The box indicates the cell shown in $B$. (B) HVEM photomicrograph of a single cell (box in $A$ ) reveals the distribution of colloidal-gold particles. The gold signal indicates that the RNA is distributed around the cytoplasm. Bar, $0.5 \mu$. $(C)$ Sketch of opsin Rhl protein localization in a $0.2-\mu$ cryosectioned retina from a newly emerged fly. The data are presented in this manner to reveal the overall distribution of the colloidal-gold particles. The spots represent the positions of individual gold particles, which are abundant in the rhabdomeres. Conventional, 100-KeV EM. $(D)$ Conventional electron micrograph of a single cell (box in $C)$. The colloidal-gold signal is abundant on the rhabdomeric membranes. Bar, $0.5 \mu$. 

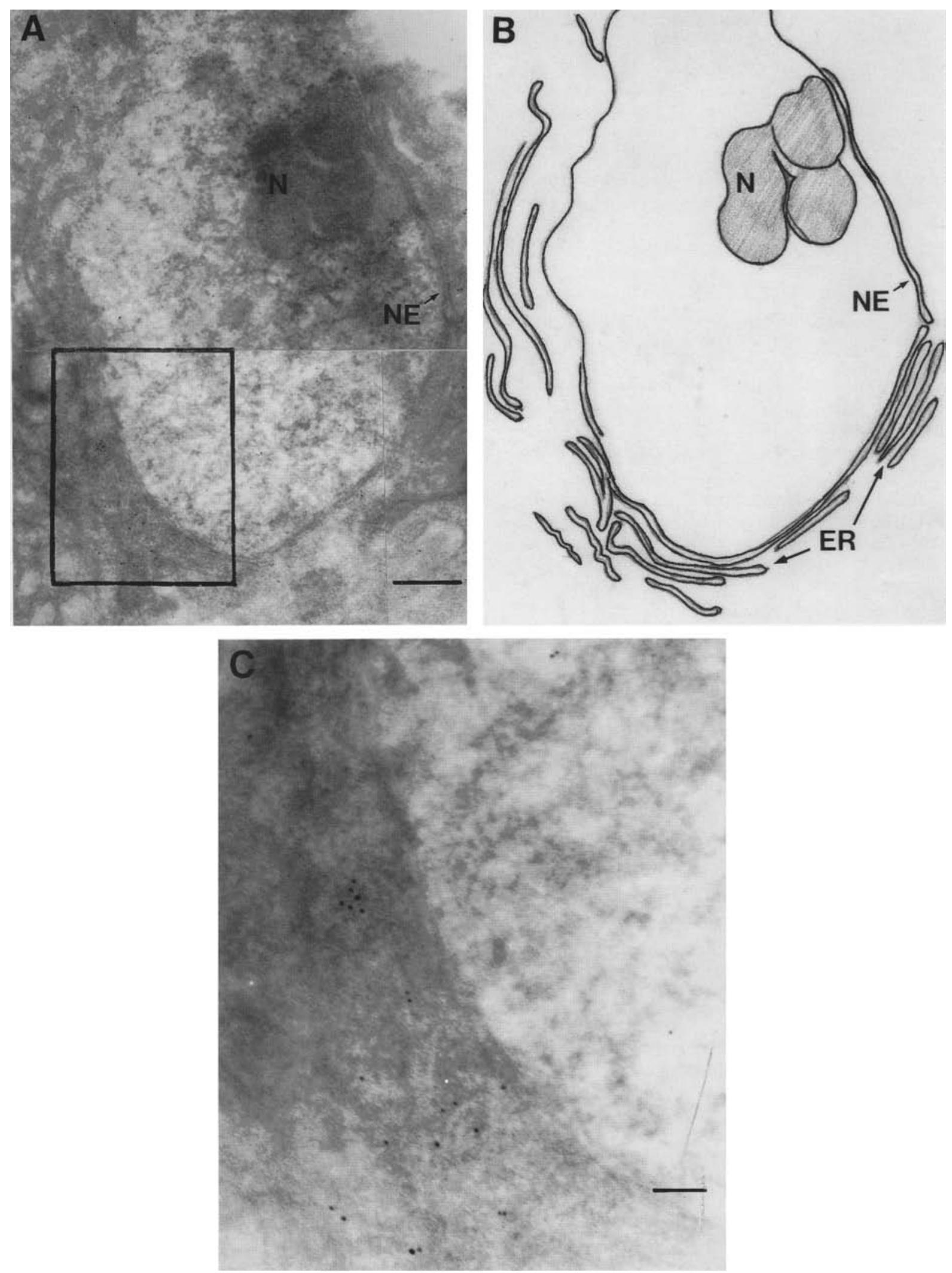

Figure 8. (See following page for legend.) 
that their abundance decreases at a greater distance from the cell nuclei, regardless of whether their transport is an active or passive process. However, the mutant transcripts appear to occur at normal steady-state levels in the adult retina (Van Vactor et al. 1988), suggesting that these transcripts may have normal stability. Both chaoptic mutant transcripts have normal 5' ends (Van Vactor et al. 1988), suggesting that they would be capped; both mutant transcripts have poly $(\mathrm{A})^{+}$tails, a structural feature that has been implicated in mRNA stability (Brawerman 1987). Thus, the mutant transcripts have at least some of the basic structural features that appear to be necessary for stabilizing the mRNA within the cell. However, chp2 is fused to a foreign sequence at its $3^{\prime}$ end, which could make it susceptible to degradation. In vitro studies of mRNA stability or measurements of turnover in vivo may cast light on this question.

An alternative mechanism that would explain our observations of a graded distribution of transcript would be that the mutant transcripts are defective in specific transport. Movement of chaoptic mRNA from the apically positioned nuclei of cells $R 1-R 7$ to their basal poles may be needed for local production of chaoptin protein for the developing microvilli. Because the photoreceptor cells are quite long, it is reasonable to conjecture that an active transport mechanism would be necessary to sustain the constant demand of precursors needed for the massive growth of the rhabdomeres throughout the cell's depth. In mature photoreceptors, continued production of the protein may be required to replenish rhabdomeric membranes during membrane turnover (Carlson and Chi 1979), and the overall distribution within the cell may need to be under strict control to preserve the high degree of cellular structure.

mRNA transport and localization may be mediated through interactions with its nascent protein product (Singer et al. 1989) and/or through direct interaction of the RNA with proteins binding to the $3^{\prime}$-untranslated region or elsewhere. Yisraeli and Melton (1988) have shown that Vgl mRNA, injected into cultured frog oocytes, undergoes correct localization, even in the absence of translation. Their results suggest that polarity information is present in the naked mRNA, which interacts directly with cytoskeletal proteins. Recently, Yisraeli and Melton (1990) have gone on to use cytoskeletal inhibitors and have obtained results that suggest that microtubules are important for transport and localization of $\mathrm{Vg} 1$ and that microfilaments are important for anchoring the message, once localized. Macdonald and Struhl (1988) have shown that sequences spanning $\sim 625$ $\mathrm{bp}$ of the 3'-untranslated region of the bicoid mRNA are both necessary and sufficient to cause specific localiza- tion. This may be achieved via secondary structure and specific protein-binding recognition sequences.

In the case of chaoptic, we saw that in the chp2 allele, a severely abnormal distribution occurred when the $3^{\prime}-$ untranslated sequence was eliminated. This was correlated with striking defects in cellular morphogenesis. In the chp1 allele, however, the molecular change in the mutant transcript is relatively small; the transcript and protein are of essentially normal size. Yet, the transcript distribution was abnormal. It is conceivable that in this case, an alteration in the nascent protein, affecting its interaction with the endomembrane system, could be responsible. The two mutants studied here are not adequate to answer these questions specifically, but the results suggest that this assay system could be used, in conjugation with site-directed in vitro mutagenesis, to identify the specific features of the transcript that are instrumental in controlling its distribution.

The new, high-resolution EM in situ hybridization technique described has allowed us to show that the chaoptic RNA is not randomly distributed in the cytoplasm of the cell but is associated with discrete patches of rough endoplasmic reticulum. Studies on the endomembrane system have suggested that the rough endoplasmic reticulum can be specifically shuttled through the cell on the cytoskeletal network (Dabora and Sheetz 1988; Lee and Chen 1988; Dailey and Bridgman 1989). Matsumoto-Suzuki and co-workers (1989) have performed an analysis of the intracellular endomembrane network in the Drosophila compound eye photoreceptor cells and have found that the subretinal cysternae, which appear to generate the rhabdomeric microvilli, are continuous with both the rough endoplasmic reticulum and the Golgi apparatus. Furthermore, their results suggest that the rough endoplasmic reticulum is shuttled through the depth of the photoreceptor cell along the side of the cell opposite the rhabdomeres, a result that is consistent with our HVEM observations (data not shown). Continued refinement and application of highresolution ultrastructural techniques, such as we have described, combined with precise manipulation of the RNA sequence, should permit the investigation of various aspects of the molecular cell biology of mRNA transport and localization as it relates to the physiology of developing and mature neurons.

\section{Experimental procedures}

\section{Fly strains}

The wild-type, normal strain of Drosophila melanogaster used in this study was Oregon- $\mathrm{R}$. The X-ray-induced chaoptic mutant alleles, chp1, maintained in heterozygous form over a covering deficiency $D f(3 R) t l^{E}$, and chp2, which was used in homo-

Figure 8. HVEM of a nucleus probed for chaoptic RNA reveals a nonuniform association with rough endoplasmic reticulum. (A) HVEM of a photoreceptor nucleus after in situ hybridization with biotinylated chaoptic cDNA. (N) Nucleolus; (NE) nuclear envelope. Bar, $0.5 \mu$. Boxed region is shown at higher magnification in $C$. $\{B \mid$ Sketch of the HVEM shown in $A$. The drawing represents the relationship of the endoplasmic reticulum to the nuclear envelope $(\mathrm{NE})$. $(C)$ High-magnification view (boxed region in $A)$ of the nuclear envelope and endoplasmic reticulum. The colloidal-gold particles are clearly visible and appear to be associated with discrete patches of rough endoplasmic reticulum. Bar, $0.13 \mu$. 
zygous form, were provided by S.L. Zipursky (Van Vactor et al. 1988). The opsin Rhl-deficient mutant $D f(3 R)$ oI17 nina $\mathrm{E}$ was provided by W.L. Pak (O'Tousa et al. 1985). The flies were reared with a normal 12 -hr day/12-hr night cycle at $25^{\circ} \mathrm{C}$ and relative humidity $65 \%$.

\section{Molecular clones}

The clones used were $\lambda$-Dm24B10 (Zipursky et al. 1984), provided by S.L. Zipursky, and its corresponding full-length cDNA (Reinke et al. 1988), provided by R. Reinke. The opsin clone (Zuker et al. 1985) was provided by C. Zuker.

For the in situ hybridization experiments, the cloned DNA inserts were cut out with restriction enzymes and separated on an agarose gel, and the Drosophila sequences were purified with Whatman DE81 ion exchange paper. ${ }^{3} \mathrm{H}$-Labeled DNA probes were prepared by nick-translation with all four labeled nucleotides, following the procedures of Hafen and Levine (1986), and resulting in a sp. act. of $\sim 5 \times 10^{7} \mathrm{cpm} / \mathrm{mg}$ of DNA.

Gel-purified, restriction-digested Drosophila DNA was biotin-labeled by nick-translation with biotinylated dUTP and biotinylated dCTP (Enzo). The biotin-labeled reaction mixture was size-selected for the range of $50-250$ bp by agarose gel electrophoresis and Whatman DE81 ion exchange paper.

\section{Tissue isolation}

Third-instar larvae were collected after they had crawled out of the food. Prepupae and pupae were staged by floating and by pigmentation, as described previously (Mitchell and Petersen 1982; Baneriee et al. 1987a).

\section{Cryomicrotomy}

Cryostat sections of larvae and prepupae were made by embedding whole animals in Tissuetek OCT compound while the cryostat chuck sat on a block of dry ice, with forceps being used for orientation. Pupae (aged $12 \mathrm{hr}$ old or older) were dissected from the pupal case prior to embedding. The specimens were equilibrated to $-18^{\circ} \mathrm{C}$ for sectioning on a Tissuetek cryostat.

\section{Light microscopic immunohistochemistry}

Cryosections, 2-8 $\mu$ thick, were picked up on glass slides and air-dried for $20 \mathrm{~min}$ to $2 \mathrm{hr}$. Immunostaining was performed at room temperature in a humidified plastic box. The tissue was fixed at room temperature by passing the microscope slides through a graded acetone series $20 \%$ for $2 \mathrm{~min}, 50 \%$ for $2 \mathrm{~min}$, $80 \%$ for $2 \mathrm{~min}$, and $100 \%$ for $10 \mathrm{~min}$ ), rehydrated and washed twice for $5 \mathrm{~min}$ in TBS [Tris-buffered saline: $100 \mathrm{~mm}$ Tris- $\mathrm{HCl}$ (pH 7.5), $130 \mathrm{~mm} \mathrm{NaCl}, 5 \mathrm{~mm} \mathrm{KCl}, 5 \mathrm{~mm} \mathrm{NaN}_{3}$ ]. Acetone fixation eliminates the eye pigments, which otherwise autofluoresce. In addition, acetone fixation specifically enhances the strength of MAb24B10 staining. Hybridoma supernatant diluted $1: 1$ with TBS was used to cover the tissue, which was incubated for 15-30 min at room temperature, followed by a 5 -min wash in TBS. The secondary antibody, FITC-goat antimouse IgG, $1: 50$ in TBS, was applied for $15 \mathrm{~min}$, followed by a 5 -min wash in TBS. Coverslips were mounted with $90 \%$ glycerol containing $0.1 \%$ phenylenediamine (buffered to $\mathrm{pH} 7.5$ with $1.0 \mathrm{M}$ Tris base) to inhibit fading of fluorescence.

\section{Light microscopic in situ hybridization}

Tissue sections were prepared by fixation in $4 \%$ paraformaldehyde and pretreatment with $0.2 \mathrm{~N} \mathrm{HCl}$ and $2 \times \mathrm{SSC}$, as described by Hafen and Levine (1986), with the following exceptions. Pronase was not used. Hybridization times were 6-12 hr at $37^{\circ} \mathrm{C}$ in a humidified chamber. After hybridization, the tissue was washed in washing buffer $[50 \%$ formamide, $0.6 \mathrm{M} \mathrm{NaCl}, 10$ $\mathrm{mM}$ Tris- $\mathrm{HCl}$ ( $\mathrm{pH} 7.5$ ), $1 \mathrm{~mm}$ EDTA] for $8-12 \mathrm{hr}$ with at least 10 changes of washing buffer. Exposure of Kodak NTB2 photographic emulsion was carried out under desiccation at $4^{\circ} \mathrm{C}$ for 6 $\mathrm{hr}$ to 7 weeks, depending on the particular probe and experiment. Background and null levels of hybridization signal were established by the following methods: (1) by use of equivalent amounts of labeled plasmid DNA; (2) by use of labeled nontranscribed Drosophila DNA; or (3) by use of the labeled positive probe on genetic null mutants that lack the corresponding transcript (see Fig. 5H).

\section{EM in situ hybridization}

The EM in situ hybridization technique differs significantly from the light microscopic procedures in the preservation of ultrastructural tissue morphology. Whereas the light microscopic procedures extract the tissue so that the endogenous mRNAs are more accessible to the labeled probes, the EM procedure employs a minimal extraction. The results yield reasonably preserved ultrastructure, but the absolute sensitivity to localized RNAs is somewhat reduced.

Tissue was dissected from developmentally staged animals under fixative [ $4 \%$ paraformaldehyde, $0.1 \%$ glutaraldehyde in PBS ( $130 \mathrm{~mm} \mathrm{NaCl}, 7 \mathrm{mM} \mathrm{Na}_{2} \mathrm{HPO}_{4}, 3 \mathrm{mM} \mathrm{NaH} \mathrm{PO}_{4}$ )] at room temperature, and the tissue was fixed for at least $\mathrm{l} \mathrm{hr}$. The tissue was cryoprotected with $0.5 \mathrm{M}$ sucrose in PBS with $2 \%$ paraformaldehyde for $1 \mathrm{hr}$ on ice and $1.0 \mathrm{M}$ sucrose in PBS with $2 \%$ paraformaldehyde for at least $1 \mathrm{hr}$ on ice, followed by $2.3 \mathrm{M}$ sucrose in PBS with $2 \%$ paraformaldehyde for at least $6 \mathrm{hr}$ on ice. The bisected heads were oriented for sectioning on ultramicrotome studs (Bullseye type) in $2.3 \mathrm{M}$ sucrose in PBS and frozen rapidly by immersion in liquid propane or Freon 22, chilled by liquid nitrogen.

Tissue was sectioned at $0.5-1.5 \mu \mathrm{m}$ on a Reichert Ultracut E/FC4D- or FC4E-equipped cryoultramicrotome at temperatures between -90 and $-100^{\circ} \mathrm{C}$. Sections were collected on beads of $2.3 \mathrm{M}$ sucrose in PBS and placed on Formvar-filmed, glow-discharged, solid gold thin bar grids (mesh 300 ). The grids were washed in PBS at room temperature for 5-15 min.

The endogenous mRNAs were made more accessible to probe by preparing the tissue in a manner similar to that used for light microscopic in situ hybridization. Upon washing the sucrose from the tissue sections on the grids with PBS, the tissue was treated with $0.1 \mathrm{~N} \mathrm{HCl}$ for $2 \mathrm{~min}$ and $2 \times$ SSC for $5 \mathrm{~min}$. During the SSC treatment, the small volume on which the grids were floating was transferred to a $70^{\circ} \mathrm{C}$ hot plate. The tissue was then fixed briefly $(4 \%$ paraformaldehyde, $0.1 \%$ glutaraldehyde in PBS) for 5 min, washed in PBS, and dehydrated through an ethanol series $(20 \%, 50 \%$, and $70 \%$ in water) for 1,2 , and $5 \mathrm{~min}$, respectively. The tissue was then rehydrated and washed in PBS. The PBS was exchanged for hybridization buffer, and the grids were transferred to $37^{\circ} \mathrm{C}$ for $30 \mathrm{~min}$. The grids were individually hybridized on $18-\mu$ l drops of hybridization mix with biotinylated probe DNA at a concentration of $1.7 \mu \mathrm{g} / \mathrm{ml}$ for $6-8$ $\mathrm{hr}$ at $37^{\circ} \mathrm{C}$.

After hybridization, the grids were floated on hybridization wash buffer prewarmed to $37^{\circ} \mathrm{C}$ and transferred to fresh wash buffer over a 4-hr period $\sim 20$ times. Beginning at the fifth hour, the hybridization wash buffer was exchanged with PBS. Once in PBS, the grids were cooled to room temperature and washed for another $30 \mathrm{~min}$ with two to three changes of buffer.

The specific hybrids of endogenous RNA coupled with biotinylated probe DNA were detected by employing antibiotin antibody, which was, in turn, detected with antibodies conju- 
gated with $10-\mathrm{nm}$ gold, following previously described procedures (Tokuyasu 1984; Van den Pol et al. 1989).

\section{$E M$}

Immunogold-labeled thin cryosections were examined at 100 $\mathrm{KeV}$ by using a JEOL JEM $100 \mathrm{CX}$ EM. Semithick cryosections $(0.5-1.0 \mu \mathrm{m})$ were examined at $1000 \mathrm{KeV}$ with the aid of a JEM 1000 high-voltage EM located in Boulder, Colorado (National Institutes of Health, National Facility for High Voltage Electron Microscopy, University of Colorado).

\section{Acknowledgments}

We express our thanks to Larry Zipursky, Rosemary Reinke, Dave Van Vactor, and their co-workers for their help and generosity. We also thank Charles Zuker for the ninaE clone and Herschel Mitchell for sharing his wealth of knowledge. We are indebted to Nancy Bonini, Utpal Banerjee, and Susan Celnicker, whose comments on this work and this paper were invaluable. Ultracryomicrotomy was performed by Thomas Deerinck. Expert technical assistance was provided by Marika Anderson, Julia Chang, Eveline Eichenberger, Jenny Mao, and Rosalind Young. George Wray, Paul Connaly, and Mary Morphew provided technical support for the HVEM work in Boulder, Colorado. This work was supported by grants from the National Institutes of Health (NIH) (EY05863 and EY08334-01 to J.A.P.; NS 14718, NS26739, and RR04050 to M.H.E.; and P01-GM40499 to S.B.) and from the National Science Foundation (BNS 88-10098 to M.H.E and DCB-8409366 to S.B.), as well as by a developmental biology grant from the Lucille P. Markey Charitable Trust to J.A.P. and S.B. The HVEM facilities in Boulder, Colorado, were supported by the NIH Division of Research Resources (RR 00592); J.A.P. was the recipient of an HVEM Scholar Award from this facility.

\section{References}

Banerjee, U., P.J. Renfranz, J.A. Pollock, and S. Benzer. 1987a. Molecular characterization and expression of sevenless, a gene involved in neural pattern formation in the Drosophila eye. Cell 49: 281-291.

Banerjee, U., P.J. Renfranz, D.R. Hinton, B.A. Rabin, and S. Benzer. 1987b. The sevenless protein is expressed apically in cell membranes of developing Drosophila retina; it is not restricted to cell R7. Cell 51: 151-158.

Bloomquist, B.T., R.D. Shortridge, S. Schneuwly, M. Perdew, C. Montell, H. Steller, G. Rubin, and W.L. Pak. 1988. Isolation of a putative phospholipase C gene of Drosophila, norpA, and its role in phototransduction. Cell 54: 723-733.

Bonneau, A.M., A. Darveau, and N. Sonenberg. 1985. Effect of viral infection on host protein synthesis and mRNA association with the cytoplasmic cytoskeletal structure. I. Cell Biol. 100: 1209-1218.

Braitenberg, V. 1967. Patterns of projection in the visual system of the fly. I. Retina-lamina projections. Exp. Brain Res. 3: $271-298$.

Brawerman, G. 1987. Determinants of messenger RNA stability. Cell 48: 5-6.

Carlson, S.D. and C. Chi. 1979. The functional morphology of the insect photoreceptor. Annu. Rev. Entomol. 24: 379416.

Cowman, A.F., C.S. Zuker, G.M. Rubin. 1986. An opsin gene expressed in only one photoreceptor cell type of the Drosophila eye. Cell 44: 705-710.

Dabora, S.L. and M.P. Sheetz. 1988. The microtubule-dependent formation of a tubulovesicular network with charac- teristics of the endoplasmic reticulum from cultured cell extracts. Cell 54: 27-35.

Dailey, M.E. and P.C. Bridgman. 1989. Dynamics of the endoplasmic reticulum and other membranous organelles in growth cones of cultured neurons. I. Neurosci. 9: 18971909.

Edgar, B.A., G.M. Odell, and G. Schubiger. 1987. Cytoarchitecture and the patterning of fushi tarazu expression in the Drosophila blastoderm. Genes Dev. 1: 1226-1237.

Ellisman, M.H. and K.R. Porter. 1980. The microtrabecular structure of the axoplasmic matrix: visualization of crosslinking structures and their distribution. J. Cell Biol. 87: 464-479.

Farmer, S.R., A. Ben-Ze'ev, B.J. Benecke, and S. Penman. 1978. Altered translatability of messenger RNA from suspended anchorage-dependent fibroblasts: Reversal upon cell attachment to a surface. Cell 15: 627-637.

Fryxell, K.J. and E.M. Meyerowitz. 1987. An opsin gene that is expressed only in the R7 photoreceptor cell of Drosophila. EMBO 6: 443-451.

Fujita, S.C., S.L. Zipursky, S. Benzer, A. Ferrus, and S.L Shotwell. 1982. Monoclonal antibodies against the Drosophila nervous system. Proc. Natl. Acad. Sci. 79: 7929-7933.

Fulton, A.B., K.W. Wan, and S. Penman. 1980. The spatial distribution of polyribosomes in $3 \mathrm{~T} 3$ cells and the associated assembly of proteins into the cytoskeletal framework. Cell 20: $849-857$.

Garner, C.C., R.P. Tucker, and A. Matus. 1988. Selective localization of messenger RNA for cytoskeletal protein MAP2 in dendrites. Nature 336: 674-677.

Gert de Couet, H. and T. Tanimura. 1987. Monoclonal antibodies provide evidence that rhodopsin in the outer rhabdomeres of Drosophila melanogaster is not glycosylated. Eur. I. Cell Biol. 44: 50-56.

Hafen, E. and M. Levine. 1986. The localization of RNAs in Drosophila tissue sections by in situ hybridization. In: Drosophila, a practical approach (ed. D.B. Roberts), pp. 139-157. IRL Press, Oxford/Washington, D.C.

Hammerschlage, R., G.C. Stone, J.D. Lindsay, and M.H. Ellisman. 1982. Evidence that all newly synthesized proteins destined for fast axonal transport pass through the Golgi apparatus. I. Cell Biol. 93: 568-575.

Hyde, D.R., K.L. Mecklenburg, J.A. Pollock, T.S. Vihtelic, and S. Benzer. 1990. 20 Drosophila visual system cDNA clones; one is a homolog of human arrestin. Proc. Natl. Acad. Sci. 87: $1008-1012$.

Lawrence, J.B. and R.H. Singer. 1986. Intracellular localization of messenger RNAs for cytoskeletal proteins. Cell 45: 407415.

Lee, C. and L.B. Chen. 1988. Dynamic behavior of endoplasmic reticulum in living cells. Cell 54: 37-46.

Lenk, R. and S. Penman. 1979. The cytoskeletal framework and poliovirus metabolism. Cell 10: 67-78.

Lenk, R., L. Ransom, Y. Kaufman, and S. Penman. 1977. A cytoskeletal structure with associated polyribosomes obtained from Hela cells. Cell 10: 67-78.

Lindsay, J.D. and M.H. Ellisman. 1985a. The neuronal endomembrane system. I. Direct links between rough endoplasmic reticulum and the cis element of the Golgi apparatus. I. Neurosci. 5: 3111-3123.

- 1985b. The neuronal endo-membrane system. II. The multiple forms of the Golgi apparatus cis element. I. Neurosci. 5: 3124-3134.

- 1985c. The neuronal endo-membrane system. III. The origins of the axoplasmic reticulum and discrete axonal cisternae at the axon hillock. I. Neurosci. 5: 3135-3144.

Macdonald, P.M. and G. Struhl. 1988. Cis-acting sequences re- 
sponsible for anterior localization of bicoid mRNA in Drosophila embryos. Nature 336: 595-598.

Matsumoto-Suzuki, E., K. Hirosawa, and Y. Hotta. 1989. Structure of the subrhabdomeric cisternae in the photoreceptor cells of Drosophila melanogaster. J. Neurocytol. 18: 87-93.

Melton, D.A. 1987. Translocation of a localized maternal mRNA to the vegetal pole of Xenopus oocytes. Nature 328: $80-82$.

Mitchell, H.K. and N.S. Petersen. 1982. Developmental abnormalities in Drosophila induced by heat shock. Dev. Genet. 3: $91-102$.

Mlodzik, M. and W.J. Gehring. 1987. Expression of the caudal gene in the germ line of Drosophila: Formation of an RNA and protein gradient during early embryogenesis. Cell 48: $465-478$.

Montell, C., K. Jones, E. Hafen, and G. Rubin. 1985. Rescue of Drosophila phototransduction mutation trp by germ line transformation. Science 230: 1040-1043.

Montell, C., K. Jones, C.S. Zuker, and G.M. Rubin. 1987. A second opsin gene expressed in the ultraviolet sensitive R7 photoreceptor cells of Drosophila melanogaster. J. Neurosci. 7: 1558-1566.

Nüsslein-Volhard, C., G.H. Frohnhofer, R. Lehmann. 1987. Determination of anteroposterior polarity in Drosophila. Science 238: 1675-1681.

O'Tousa, J.E., E.W. Baehr, R.L. Martin, J. Hirsh, W.L. Pak, and M.L. Applebury. 1985. The Drosophila ninaE gene encodes an opsin. Cell 40: 839-850.

Pollock, J.A. and S. Benzer. 1988. Transcript localization of four opsin genes in the three visual organs of Drosophila; Rh2 is ocellus specific. Nature 333: 779-782.

Pondel, M.D. and M.L. King. 1988. Localized maternal mRNA related to transforming growth factor $\beta$ mRNA is concentrated in a cytokeratin-enriched fraction from Xenopus oocytes. Proc. Natl. Acad. Sci. 85: 7612-7616.

Ready, D.F. 1989. A multifaceted approach to neural development. Trends Neurosci. 12: 102-110.

Reinke, R., D.E. Krantz, D. Yen, and S.L. Zipursky. 1988. Chaoptin, a cell surface glycoprotein required for Drosophila photoreceptor cell morphogenesis contains a repeat motif found in yeast and human. Cell 52: 291-301.

Schaeffer, E., D. Smith, G. Mardon, W. Quinn, and C. Zuker. 1989. Isolation and characterization of two new Drosophila protein kinase $\mathrm{C}$ genes, including one specifically expressed in photoreceptor cells. Cell 57: 403-412.

Shieh, B.-H., M.A. Stamnes, S. Seavello, G.L. Harris, and C.S. Zuker. 1989. The ninaA gene required for visual transduction in Drosophila encodes a homologue of cyclosporin Abinding protein. Nature 338: 67-70.

Singer, R.H., G.L. Langevin, and J.B. Lawrence. 1989. Ultrastructural visualization of cytoskeletal mRNAs and their associated proteins using double-label in situ hybridization. J. Cell. Biol. 108: 2343-2353.

Smith, D.P., B.-H. Shieh, and C. Zuker. 1990. Proc. Natl. Acad. Sci. (in press).

Strausfeld, N.J. 1976. Atlas of an insect brain. Springer-Verlag, Berlin Heidelberg/New York.

Tokuyasu, K.T. 1984. Immuno-cryoultramicrotomy. In Immunolabeling for electron microscopy (ed. J.M. Pollak and I.M. Varndell), pp. 71-82. Elsevier, Amsterdam.

Tomlinson, A. and D.F. Ready. 1987. Neuronal differentiation in the Drosophila ommatidium. Dev. Biol. 120: 366-376.

Tomlinson, A., D.D.L. Bowtell, E. Hafen, and G.M. Rubin. 1987. Localization of the sevenless protein, a putative receptor for positional information, in the eye imaginal disc of Drosophila. Cell 51: 143-150.

Trujillo-Cenoz, O. and J. Melamed. 1966. Compound eye of
Dipterans: Anatomical basis for integration-an electron microscope study. J. Ultrastruct. Res. 16: 395-398.

Van den Pol, A.N., M.H. Ellisman, and T.J. Deerinck. 1989. Plasmalemmal localization of proteins with gold immunocytochemistry. In Colloidal gold: methods and application. (ed. M.A. Hayat), pp. 451-487. Academic Press, San Diego.

Van Vactor, D., D.E. Krantz, R. Reinke, and S.L. Zipursky. 1988. Analysis of mutants in chaoptin, a photoreceptor cellspecific glycoprotein in Drosophila, reveals its role in cellular morphogenesis. Cell 52: 218-290.

Venkatesh, T.R., S.L. Zipursky, and S. Benzer. 1985. Molecular analysis of the development of the compound eye in Drosophila. Trends Neurosci. 8: 251-257.

Weeks, D.L. and D.A. Melton. 1987a. A maternal mRNA localized to the animal pole of Xenopus eggs encodes a subunit of mitochondrial ATPase. Proc. Natl. Acad. Sci. 84: 27982802.

-1987b. A maternal mRNA localized to the vegetal hemisphere in Xenopus eggs codes for a growth factor related to TGF-beta. Cell 51: 861-867.

Yisraeli, J.K. and D.A. Melton. 1988. The maternal mRNA Vgl is correctly localized following injection into Xenopus oocytes. Nature 336: 592-595.

Yisraeli, J.K. and D.A. Melton. 1990. A two-step model for the localization of maternal mRNA in Xenopus oocytes: Involvement of microtubules and microfilaments in translocation and anchoring of $\mathrm{Vgl}$ and mRNA. Development 108: $289-298$.

Zipursky, S.L., T.R. Venkatesh, D.B. Teplow, and S. Benzer. 1984. Neuronal development in the Drosophila retina: Monoclonal antibodies as molecular probes. Cell 36: 15-26.

Zipursky, S.L., T.R. Venkatesh, and S. Benzer. 1985. From monoclonal antibody to gene for a neuron-specific glycoprotein in Drosophila. Proc. Nat1. Acad. Sci. 82: 1855-1859.

Zuker, C.S., A.F. Cowman, and G.M. Rubin. 1985. Isolation and structure of a rhodopsin gene from $D$. melanogaster. Cell 40: $851-858$.

Zuker, C.S., C. Montell, K.R. Jones, T. Laverty, and G. Rubin. 1987. A rhodopsin gene expressed in photoreceptor cell R7 of the Drosophila eye: Homologies with other signal transducing molecules. J. Neurosci. 7: 1550-1557.

\section{Note added in proof}

The rne mutant $E$. coli strain used in our experiments expresses a thermolabile ribonuclease E (Misra, T.K. and D. Apirion. 1980. Gene rne affects the structure of the ribonucleic acid processing enzyme ribonuclease E of Escherichia coli. I. Bacteriol. 142: 359-361). Reversion of the temperature-sensitive growth phenotype correlates with restoration of 9S RNA processing (Apirion, D. 1978. Isolation, genetic mapping and some characterization of a mutation in Escherichia coli that affects the processing of ribonucleic acid. Genetics 90: 659-671). We isolated twelve independent, spontaneous revertants which formed colonies at $43^{\circ} \mathrm{C}$. Eight of the revertants produced normal levels of 5S RNA, whereas the remaining four made subnormal levels and accumulated 9S RNA precursor. Two of the revertants with only partial 9S RNA processing formed small colonies at $43^{\circ} \mathrm{C}$. In all of the revertants, processing at the -71 site of the T4 gene 32 mRNA in infected cells correlated with the level of $9 \mathrm{~S}$ RNA processing in uninfected cells. Thus, there is no indication that the activity that processes 9S RNA and gene 32 mRNA can be separated genetically. The correlation between the levels of 9S RNA and gene 32 mRNA processing is compatible with a direct role for RNase $\mathrm{E}$ in the cleavage of gene 32 mRNA at the -71 site. 


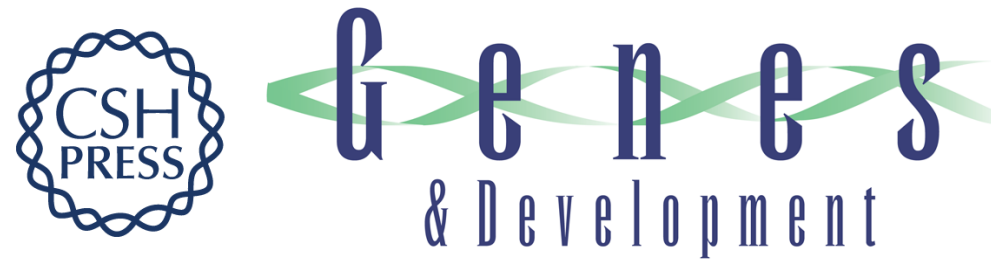

\section{Subcellular localization of transcripts in Drosophila photoreceptor neurons: chaoptic mutants have an aberrant distribution.}

J A Pollock, M H Ellisman and S Benzer

Genes Dev. 1990, 4:

Access the most recent version at doi:10.1101/gad.4.5.806

References This article cites 56 articles, 19 of which can be accessed free at: http://genesdev.cshlp.org/content/4/5/806.full.html\#ref-list-1

License

Email Alerting

Receive free email alerts when new articles cite this article - sign up in the box at the top Service right corner of the article or click here.

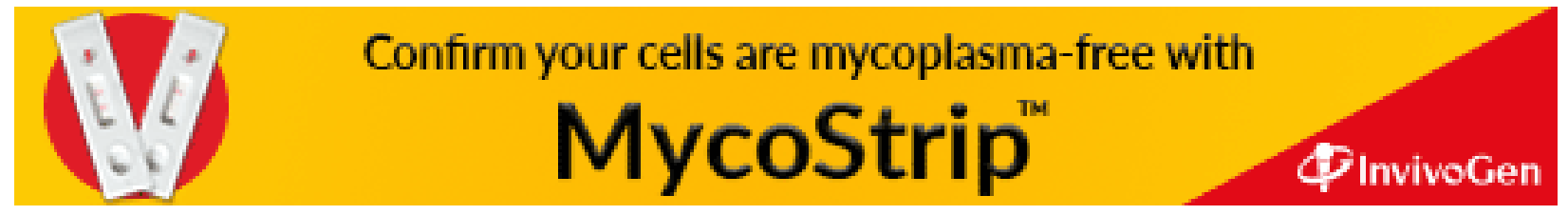

